\title{
Anterior Encephalocele and Its Association with MTHFR Polymorphisms: A Case-Control Study
}

\author{
Hemonta K. Dutta ${ }^{1}$ Debasish Borbora ${ }^{2}$ Mauchumi Baruah ${ }^{3}$ Kanwar Narain ${ }^{4}$ \\ ${ }^{1}$ Department of Pediatric Surgery, Assam Medical College \& Hospital, \\ Dibrugarh, Assam, India \\ 2 Department of Biotechnology, Gauhati University, \\ Guwahati, Assam, India \\ ${ }^{3}$ Department of Physiology, Assam Medical College, \\ Dibrugarh, Assam, India \\ ${ }^{4}$ Regional Medical Research Laboratory, ICMR, Lahowal, \\ Dibrugarh, Assam, India \\ Indian J Neurosurg 2017;6:184-188.

\begin{abstract}
Address for correspondence Hemonta K. Dutta, MBBS, MS, MCh, Department of Pediatric Surgery, Assam Medical College \& Hospital, Dibrugarh 786002, Assam, India (e-mail: drhemontad@rediffmail.com).
\end{abstract}

\section{Introduction}

Anterior encephalocele $(\mathrm{AE})$ is a rare congenital anomaly of the central nervous system characterized by protrusion of the intracranial content beyond the normal confinement of the
Background Neural tube defects (NTDs) are thought to be associated with genetic defects and environmental factors. This study aims to determine the association of MTHFR gene polymorphisms and maternal body mass index (BMI) with anterior encephalocele (AE).

Methods Blood samples of 20 patients (out of 41 children) were available for genetic analysis. Genomic DNA was extracted from whole blood samples using Wizard genomic DNA purification kit. The MTHFR C677T and A1298C polymorphisms genotyping protocols were adapted from Cicek et al. Eighty-two age- (1-14 years) and sexmatched apparently healthy children were taken as controls. We assessed the nutritional status of all the volunteers by measuring their BMI and then classified according to WHO BMI cutoff points.

Results Nasofrontal AE was seen mostly among the female cases while among males, nasoethmoidal AE was predominant. We observed a weak association between MTHFR 677CT genotype and AE. In the case of MTHFR A1298C, both the 1298AC and 1298CC genotypes increased the risk of acquiring AE by several folds. Multivariate analysis revealed that both $1298 \mathrm{AC}$ and $1298 \mathrm{CC}$ genotypes increased the risk of acquiring AE. However, only 1298 AC was significantly associated with the risk of AE. The study also showed significantly low BMI among the children and their mothers.

Conclusion There is a strong association between MTHFR A1298C polymorphism and the risk of anterior encephalocele in this community. The C677T polymorphism, however, did not constitute a genetic risk factor in this study. Children with $A E$ also had significantly low BMI. received

November 18, 2016

accepted

July 3, 2017

published online

October 13, 2017 cranium. It is a visible defect at the root of the nose and hence also called as "sincipital" (-Fig. 1). Sporadic in the western world, $\mathrm{AE}$ cases are most frequently reported from the developing nations of Southeast Asia where the incidence rate varies between 1 in 3,000 and 1 in $5,000,{ }^{1}$ but the
DOI https://doi.org/

$10.1055 / \mathrm{s}-0037-1606821$. ISSN 2277-954X. (c) 2017 Neurological Surgeons' Society
of India

License terms

c) $(1) \$$ 


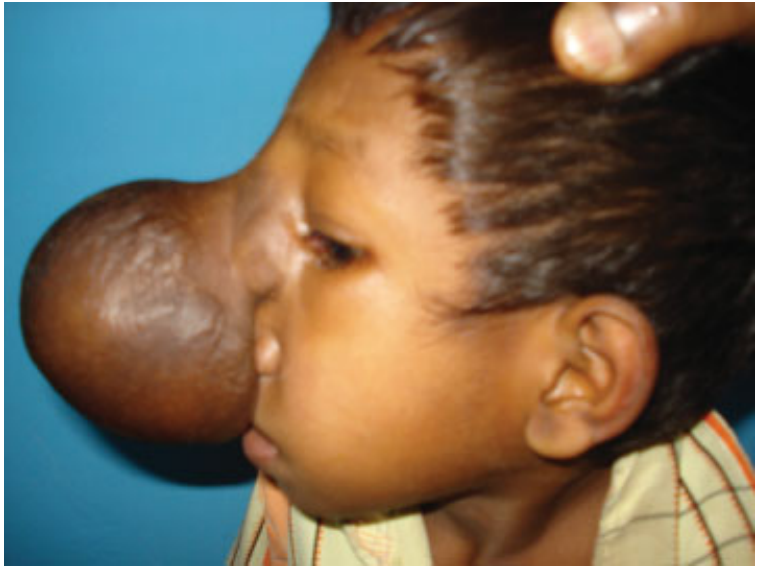

Fig. 1 A child with frontoethmoidal encephalocele.

possible explanation for its "remarkably specific geographical distribution" is still unknown. Several studies have implicated genetic predispositions, nutrition, and environmental factors as risk factors of neural tube defects (NTDs). ${ }^{2}$

Two polymorphisms in the 5,10-methylenetetrahydrofolate reductase (MTHFR) gene-the C677T (rs1801133 C > T) and A1298C (rs1801131 A > C)-have been frequently studied in context of NTDs. $^{2-6}$ MTHFR regulates the folate one-carbon metabolic pathway. Both the C677T (Ala222Val) and the A1298C (Glu429Ala) substitutions result in a decreased enzymatic activity. ${ }^{7}$ In Assam there is a high incidence of $\mathrm{AE}$, especially within its tea garden communities. ${ }^{8}$ However, there are no data concerning the risk factors of AE for this community. Therefore, this study was conducted to determine the association of MTHFR gene polymorphisms with the risk of $\mathrm{AE}$ in this region.

\section{Material and Methods}

\section{Study Population and Design}

Forty-one AE patients, who were surgically operated and followed up in the Department of Pediatric Surgery, consented to participate in this matched case-control study. The cases were classified based on anatomical finding according to the system described by Suwanwela and Suwanwela ${ }^{9}$ into nasofrontal, nasoethmoidal, and naso-orbital encephalocele. We also recruited 82 age- and sex-matched apparently healthy kids who had visited the department.

To study the probable risk factors, we administered a precoded close-ended questionnaire. We accessed the nutritional status of all the volunteers by measuring their body mass index (BMI). Parental BMI was calculated by dividing weight in kilograms by the height in meters squared $\left(\mathrm{kg} / \mathrm{m}^{2}\right)$ and classified according to the World Health Organization (WHO) BMI cutoff points. In case of children, the BMI-for-age percentile was used to interpret "weight status categories." We used the Child and Teen BMI calculator (the calculator was available at https://nccd.cdc.gov/dnpabmi/calculator.aspx). Of the 41 cases, only 21 cases approved for genetic analysis. One milliliter of peripheral whole blood was collected from all volunteers and stored at $-80^{\circ} \mathrm{C}$ until analyzed.

\section{MTHFR Polymorphism Analysis}

Genomic DNA was extracted from whole blood samples using Wizard genomic DNA purification kit (Promega). The MTHFR C677T and A1298C polymorphisms genotyping protocols were adapted from Cicek et al. ${ }^{7}$ A polymerase chain reaction (PCR) reaction mixture of $25 \mu \mathrm{L}$ was set up using GoTaq Hot start Green 2X master mix (Promega) containing nearly $200 \mathrm{ng}$ template DNA. Primer sequences for MTHFR C677T were 5'-GGT CAG AAG CT ATC AGT CT GAG-3', and 5'-CTG GGA AGA ACT CAG CGA ACT CAG-3', which produced a 494 bp PCR product. The PCR cycles were 2 minutes at $94^{\circ} \mathrm{C}$, followed by 30 cycles each of 30 seconds at $94^{\circ} \mathrm{C}, 30$ seconds at $62^{\circ} \mathrm{C}$, and 30 seconds at $72^{\circ} \mathrm{C}$ with final extension at $72^{\circ} \mathrm{C}$ for 7 minutes. The PCR product was then digested using Hinfl (Promega) at $37^{\circ} \mathrm{C}$ for 3 hours. When digested products were resolved on a $1.5 \%$ agarose gel, wild-type alleles (677C, Ala) resulted in 100and 394-bp fragments while the variant alleles (677T, Val) resulted in 100-, 165-, and 229-bp products (-Fig. 2). The MTHFR A1298C variant was amplified using primers 5'-AAG GAG GAG CTG CTG AAG ATG-3' and 5'- CTT TGC CT GTC CAC AGC ATG-3' and generated a product sized $237 \mathrm{bp}$. The cycling conditions were 5 minutes at $95^{\circ} \mathrm{C}$, followed by 30 cycles each of 30 seconds at $94^{\circ} \mathrm{C}, 30$ seconds at $63^{\circ} \mathrm{C}$, and 30 seconds at $72^{\circ} \mathrm{C}$ with final extension for 10 minutes at $72^{\circ} \mathrm{C}$. The PCR product was digested using $\mathrm{MboII}$ (Promega) at $37^{\circ} \mathrm{C}$ for an hour. A $15 \%$ acrylamide gel was used to resolve the digested products in which wild-type alleles (1298A) resulted in 27-, 26-, and 183-bp fragments whereas the variant alleles (1298C) resulted in 27- and 210-bp fragments (-Fig. 3).

\section{Statistical Analysis}

Date were analyzed using IBM SPSS Statistics 20 for Windows (IBM, SPSS Inc.). Initially a univariate analysis was performed

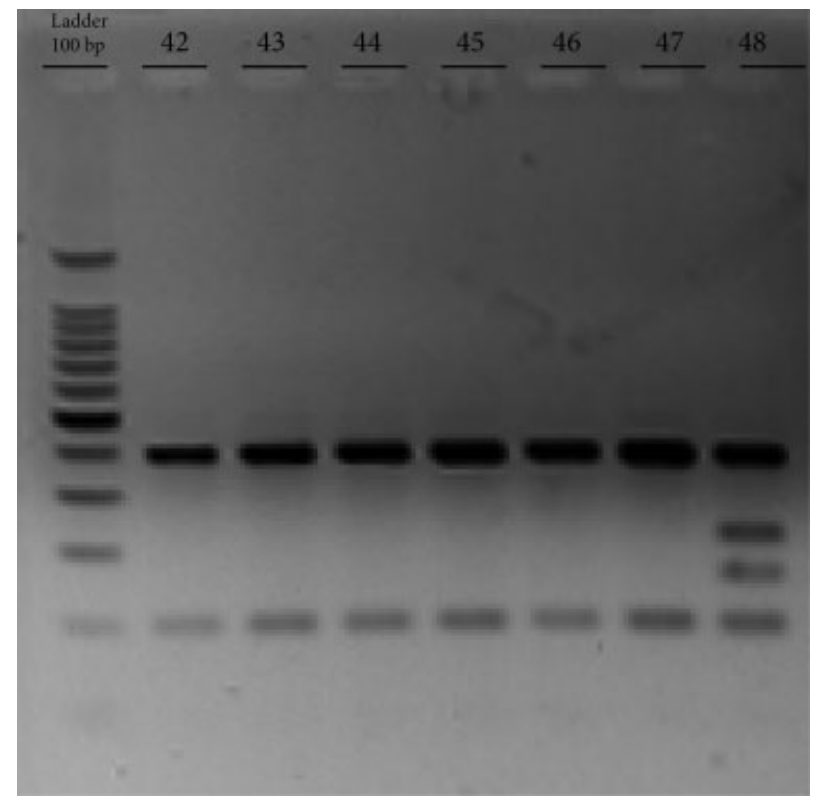

Fig. 2 PCR-RFLP analysis of MTHFR gene. The Ala allele is cleaved by Hinfl to yield two fragments (100 and 394 bp). The Val allele is cleaved by Hinfl and yields three small fragments (100, 165, and $229 \mathrm{bp})$. The heterozygote has four bands (394, 229, 165, and 100 bp). PCR-RFLP, polymerase chain reaction-restriction fragment length polymorphism. 


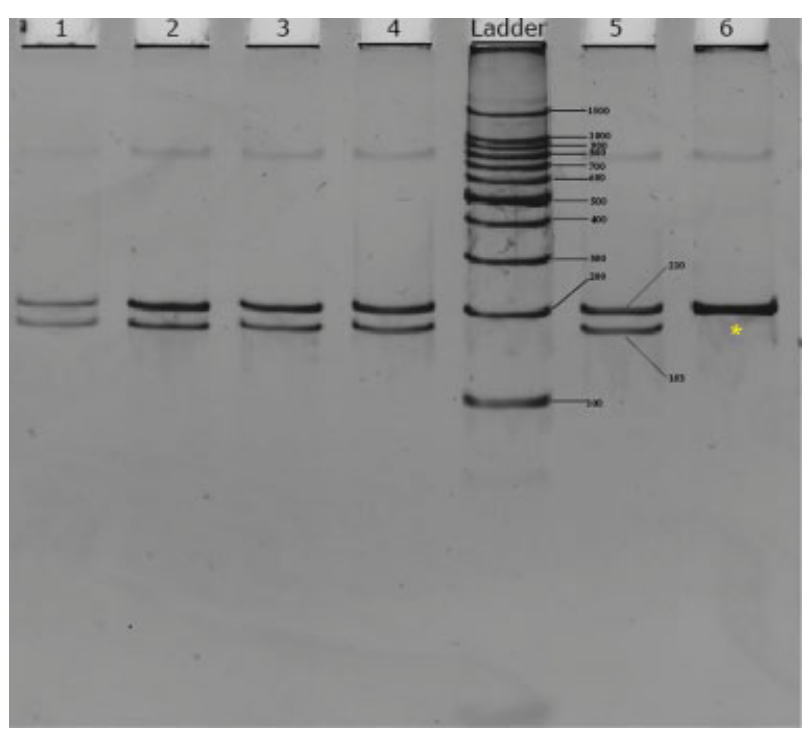

Fig. 3 MTHFR A1298C PCR-RFLP results, 100 bp ladder, 15\% PAGE. Yellow star indicates homozygous mutant. PCR-RFLP, polymerase chain reaction-restriction fragment length polymorphism.

to identify the putative risk factors. These risk factors were further analyzed using multiple logistic regression to study their independent association with AE. $p$ Value of $\leq 0.05$ (two tailed) was considered for statistical significance.

\section{Results}

Among the 41 patients who participated in the study, 20 (48.8\%) were male and $21(51.2 \%)$ were female. The mean age was 36 months, ranging from 1 to 14 years in both cases and controls. - Table 1 lists the cases according to their anatomical locations. Nasofrontal AE was seen mostly among the female cases whereas nasoethmoidal AE was predominant among males. The MTHFR C677T genotype was in Hardy-Weinberg equilibrium $(p>0.8)$, but the MTHFR A1298C departed from the same $(p=0.0)$. Data from - Table 2 revealed the risk factors associated with AE. The univariate odds ratio (OR) for MTHFR 677CT, MTHFR 1298AC, and 1298CC genotypes were 1.55 (95\% confidence interval [CI]: 0.49-3.51), 6.00 (95\% CI: 1.65-21.88), and 2.57 (95\% CI: 1.04-6.39), respectively. The analysis also indicated that a low maternal BMI significantly increased the risk of acquiring $\mathrm{AE}$.

In the multivariate analysis, there was no association between the MTHFR C677T variant genotypes and AE. The MTHFR 1298AC variant, however, was significantly associated with the risk, 7.75 (95\% CI: 1.15-52.24). The MTHFR C677T and A1298C haplotypes were not associated with the risk of AE among all the study patients. An increase in OR during the analysis indicated that low maternal BMI is an independent risk factor of $\mathrm{AE}$.

\section{Discussion}

In Assam, there is a high incidence of AE. ${ }^{8}$ Till date only a few studies have been performed to detect the possible risk factors of $\mathrm{AE}$ probably because this anomaly is predominant only in
Table 1 Cases according to anatomical locations of encephaloceles

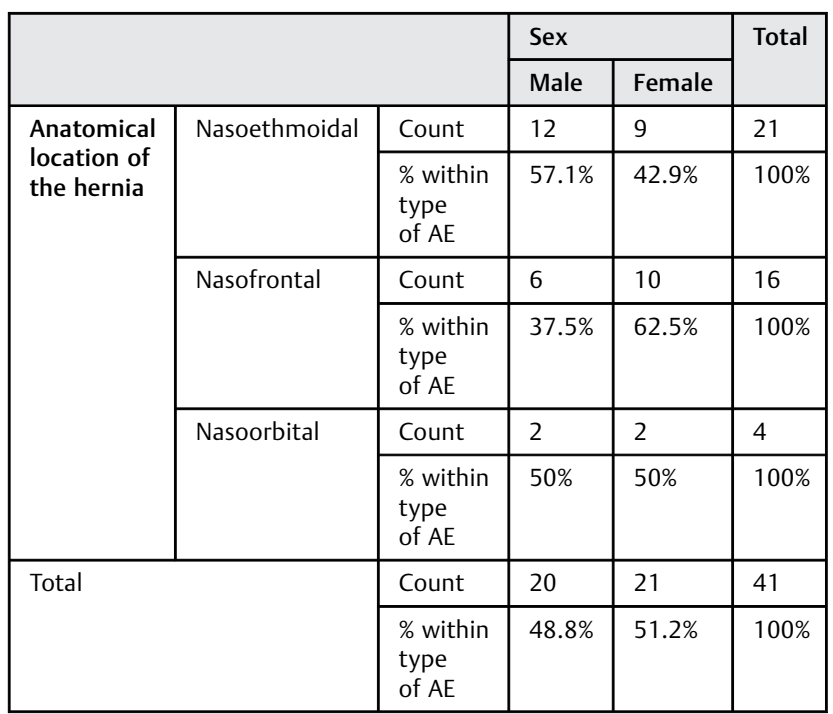

Abbreviation: $\mathrm{AE}$, anterior encephalocele.

the socioeconomically backward communities of Southeast Asia and Africa. ${ }^{2,3,5,10,11}$ The present study is the first hospitalbased case-control study to be performed in India, which studies the association between MTHFR polymorphisms and $\mathrm{BMI}$ with the risk of AE. It clearly indicates that children who carry the MTHFR 1298CC genotype were at a greater risk of having AE. Underweight children were also at a significant risk of developing AE.

Several studies have reported the C677T polymorphism as a significant risk factor of NTD, but in case of AE, these results are conflicting., ${ }^{3,12}$ In this study, we did not find any association between the MTHFR 677TT genotype and AE, as the frequency of the 677T homozygous mutant genotype among cases was zero. However, the 677CT genotype demonstrated a weak association. This observation is similar to those of studies conducted in Indonesian and Javanese community where the frequency of the 677TT genotype was close to zero. ${ }^{12}$ Homozygosity for the 677T mutation among mothers increases the risk of recurrent early pregnancy loss (REPL) by two- to threefolds in absence of folate supplementation. ${ }^{13}$ The National Family Health Survey (NFHS-3) reports that the infant mortality rate in Assam is very high and the consumption of iron folic acid among pregnant mothers at only $13.7 \%{ }^{14}$ The findings are suggestive of the significant impact of MTHFR polymorphisms in the community.

As AE is a rare event, most of the previous associative studies use a heterogeneous population of NTDs. In a recent review, Zhang et al suggested that MTHFR A1298C is not an independent risk factor of NTD, but its effect could be influenced by low dietary intake of folate and ethnicity. ${ }^{3}$ This is the first study to report a significant association between the A1298C polymorphism and the development of AE. In the multivariate analysis, both the genotypes, 1298AC and 1298CC, demonstrated a positive association with the risk of $\mathrm{AE}$, but only 1298AC achieved statistical significance. Distinct ethnicity in this region and low folate intake could explain this significant 
Table 2 Analysis of factors associated with AE

\begin{tabular}{|c|c|c|c|c|c|c|}
\hline Category & $\begin{array}{l}\text { Cases } \\
n(\%)\end{array}$ & $\begin{array}{l}\text { Control } \\
n(\%)\end{array}$ & $\begin{array}{l}\text { Crude OR } \\
(95 \% \mathrm{CI})\end{array}$ & $p$-Value & $\begin{array}{l}\text { Adjusted OR } \\
(95 \% \mathrm{Cl})\end{array}$ & $p$-Value \\
\hline \multicolumn{7}{|c|}{ MTHFR genotypes, $n(\%)^{\mathrm{a}}$} \\
\hline $677 C C$ & $14(66.7)$ & $31(73.8)$ & Ref. & & Ref. & \\
\hline $677 C T$ & $7(33.3)$ & $10(23.8)$ & $1.55(0.49-3.51)$ & 0.29 & $2.07(0.62-6.87)$ & 0.24 \\
\hline 677TT & $0(0.0)$ & $1(2.4)$ & 0.00 & 1.0 & 0.00 & 1.0 \\
\hline $1298 \mathrm{AA}$ & 11 (52.4) & 33 (78.6) & Ref. & & Ref. & \\
\hline $1298 A C$ & $4(19.0)$ & $2(4.8)$ & $6.00(1.65-21.88)$ & $0.01^{\mathrm{b}}$ & $7.75(1.15-52.24)$ & $0.04^{\mathrm{b}}$ \\
\hline $1298 C C$ & $6(28.6)$ & $7(16.7)$ & $2.57(1.04-6.39)$ & $0.04^{\mathrm{b}}$ & $1.54(1.00-24.74)$ & 0.76 \\
\hline \multicolumn{7}{|c|}{ MTHFR haplotypes } \\
\hline 677C-1298A & $22(52.4)$ & $58(69.0)$ & Ref. & & Ref. & \\
\hline 677C-1298C & $13(31.0)$ & $14(16.7)$ & $2.45(1.0-6.02)$ & $0.05^{\mathrm{b}}$ & $0.94(0.07-12.44)$ & 0.96 \\
\hline 677T-1298A & $4(9.5)$ & $10(11.9)$ & $1.06(0.30-3.71)$ & 0.93 & $0.84(0.15-4.78)$ & 0.85 \\
\hline 677T-1298C & $3(7.1)$ & $2(2.4)$ & $3.96(0.62-25.28)$ & 0.15 & $1.37(0.05-34.55)$ & 0.85 \\
\hline \multicolumn{7}{|c|}{ BMI of mother ${ }^{c}$} \\
\hline $18.5-22.9$ & $18(45.0)$ & $57(71.2)$ & Ref. & & Ref. & \\
\hline$<18.5$ & $20(50.0)$ & $22(27.5)$ & $4.89(4.13-11.21)$ & $0.00^{\mathrm{b}}$ & $6.30(2.53-15.70)$ & $0.00^{\mathrm{b}}$ \\
\hline$\geq 23$ & $2(5.0)$ & $1(1.3)$ & $4.00(0.52-30.61)$ & 0.18 & $3.77(0.42-34.12)$ & 0.24 \\
\hline
\end{tabular}

Abbreviations: $\mathrm{AE}$, anterior encephalocele; $\mathrm{BMI}$, body mass index; $\mathrm{Cl}$, confidence interval; OR, odds ratio; Ref., reference.

${ }^{a}$ These risk factors were studied in 21 cases and 42 apparently healthy controls who consented to participate in this study.

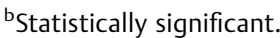

'Insufficient data.

association. In this study, we used the BMI-for-age percentile system to interpret "weight status categories" to find that underweight children were at a significantly higher risk of having $\mathrm{AE}$ as compared with healthy children. Underweight is an indicator of low socioeconomic power ${ }^{15}$ which has been previously associated with $\mathrm{AE} .^{11}$

The present study hints toward a possible association between maternal $\mathrm{BMI}$ and the risk of $\mathrm{AE}$. In the univariate analysis ( - Table 2), low maternal BMI $(<18.5$ ) was significantly associated with the risk of AE. Children of obese mothers were also at an elevated risk, but as only a small fraction of mothers in the cohort were obese, its association was not statistically significant. Although these observations were consistent with those of Stothard et al, ${ }^{16}$ according to Gao et al, maternal underweight, overweight, and obesity were not associated with elevated risks of NTDs. ${ }^{17}$

In conclusion, this study suggests a strong association between MTHFR A1298C polymorphism and the risk of AE in this community. The C677T polymorphism, however, did not constitute a genetic risk factor in this study. Children who were underweight and born to mothers having a low BMI were at an elevated risk of developing AE.

Note

This study was approved by Institutional Ethics Committee.

Funding

The funding agency had no role in study design, data collection and analysis, interpretation of results, or scripting the report. The authors had full access to the data, and the final decision to submit for publication was taken by the corresponding author.

Conflict of Interest

None.

\section{References}

1 Oucheng N, Lauwers F, Gollogly J, Draper L, Joly B, Roux FE. Frontoethmoidal meningoencephalocele: appraisal of 200 operated cases. J Neurosurg Pediatr 2010;6(06):541-549

2 Copp AJ, Stanier P, Greene ND. Neural tube defects: recent advances, unsolved questions, and controversies. Lancet Neurol 2013;12(08):799-810

3 Zhang T, Lou J, Zhong R, et al. Genetic variants in the folate pathway and the risk of neural tube defects: a meta-analysis of the published literature. PLoS One 2013;8(04):e59570

4 Bassuk AG, Kibar Z. Genetic basis of neural tube defects. Semin Pediatr Neurol 2009;16(03):101-110

5 Lacasaña M, Blanco-Muñoz J, Borja-Aburto VH, et al. Effect on risk of anencephaly of gene-nutrient interactions between methylenetetrahydrofolate reductase $\mathrm{C} 677 \mathrm{~T}$ polymorphism and maternal folate, vitamin $B_{12}$ and homocysteine profile. Public Health Nutr 2012;15(08):1419-1428

6 Harisha PN, Devi BI, Christopher R, Kruthika-Vinod TP. Impact of 5,10-methylenetetrahydrofolate reductase gene polymorphism on neural tube defects. J Neurosurg Pediatr 2010;6(04):364-367

7 Cicek MS, Nock NL, Li L, Conti DV, Casey G, Witte JS. Relationship between methylenetetrahydrofolate reductase C677T and A1298C genotypes and haplotypes and prostate cancer risk and aggressiveness. Cancer Epidemiol Biomarkers Prev 2004;13(08):1331-1336 
8 Dutta HK, Deori P. Anterior encephaloceles in children of Assamese tea workers. J Neurosurg Pediatr 2010;5(01):80-84

9 Suwanwela C, Suwanwela N. A morphological classification of sincipital encephalomeningoceles. J Neurosurg 1972;36(02):201-211

10 Muñoz JB, Lacasaña M, Cavazos RG, Borja-Aburto VH, GalavízHernández C, Garduño CA. Methylenetetrahydrofolate reductase gene polymorphisms and the risk of anencephaly in Mexico. Mol Hum Reprod 2007;13(06):419-424

11 Suphapeetiporn K, Mahatumarat C, Rojvachiranonda N, et al. Risk factors associated with the occurrence of frontoethmoidal encephalomeningocele. Eur J Paediatr Neurol 2008;12(02):102-107

12 Sadewa AH, Sunarti, Sutomo R, et al. The C677T mutation in the methylenetetrahydrofolate reductase gene among the Indonesian Javanese population. Kobe J Med Sci 2002;48 (5-6):137-144
13 Nelen WL, Steegers EA, Eskes TK, Blom HJ. Genetic risk factor for unexplained recurrent early pregnancy loss. Lancet 1997;350 (9081):861

14 Sciences IloP. National family health survey, 2007;2005-06. Mumbai, India

15 Blakely T, Hales S, Kieft C, Wilson N, Woodward A. The global distribution of risk factors by poverty level. Bull World Health Organ 2005;83(02):118-126

16 Stothard KJ, Tennant PW, Bell R, Rankin J. Maternal overweight and obesity and the risk of congenital anomalies: a systematic review and meta-analysis. JAMA 2009;301(06):636-650

17 Gao LJ, Wang ZP, Lu QB, Gong R, Sun XH, Zhao ZT. Maternal overweight and obesity and the risk of neural tube defects: a casecontrol study in China. Birth Defects Res A Clin Mol Teratol 2013; 97(03):161-165 